\title{
Determinants that Influence Consumers' Intention to Purchase Smart Watches in the UAE: A Case of University Students
}

\author{
Nasser Abdo Saif Almuraqab* \\ Dubai Business School, University of Dubai, Dubai, 14143, UAE
}

\begin{tabular}{l} 
A R T I C L E I N F O \\
\hline Article history: \\
Received: 28 December, 2020 \\
Accepted: 11 February, 2021 \\
Online: 25 February, 2021 \\
\hline Keywords: \\
Consumers \\
Smart Watches \\
Adoption \\
Purchasing intention \\
\end{tabular}

A B S T R A C T
It has been observed that the smartwatches have emerged quickly on the digital era with the
ability to significantly influence daily life and improve users' wellbeing, decisions, and
behaviour. Nonetheless they are in their stages of adoption, smartwatches are marked the
most widespread type of wearable technologies. Considering this, present work has been
carried out to intensify the scholarly understanding of determinants that affecting
consumers' behaviour of purchasing intention, to reach this objective, an integrated model
based on Technology Acceptance Model (TAM) was designed and examined. An online
questionnaire was utilized for the collected data (n=106). The empirical analysis based on
partial least square method, using SmartPLS software. The findings exposed that visibility,
social influence, and perceived ease of use are the proximate factors that drive adoption
intention. Further, the analysis reveals that Consumers'purchasing intention is significantly
influenced by intention to use and cost. The extent of these factors is influenced by
consumers'perception of smartwatches as a technology and as a fashion accessory. Present
study has also attempted to scholarly discuss the theoretical and managerial implications.

\section{Introduction}

The contemporary technological improvements and global penetration of mobile devices such as smartwatches and smartphones have resulted in anytime-anywhere real time accessibility to information. In addition, the concept of 'mobility' is advancing from simply carriable to seamlessly wearable technology. Consequently, expanding the ubiquity of personal communication to higher level. Technically, wearables are those smart electronic devices and computers that can be integrated into various kinds of daily used accessories of clothing and can be wore on or attached to the body [1]. Such devices are designed to provide consumers with a seamless and integrated experience. The major function of wearable gadgets is to help users achieve a state of self-connected by using sensors and software that simplify communication, data exchange, and instantaneously information access. Consequently, wearable devices have become a prominent part of internet of things (IOT) [2-5].

In particular, smartwatches by e.g. (Samsung, Apple, Huawei) have been highly publicized for many features and functions that attract wide range of consumers' interests, containing healthmonitoring, fitness, and location tracking and extended smart features such as communications [6]. As per the results revealed

"Corresponding Author: Nasser Abdo Saif Almuraqab, nalmarqab@gmail.com www.astesj.com

https://dx.doi.org/10.25046/aj0601142 by different recent surveys regarding smartwatch adoption, the marketplace for smartwatches will continue to grow exponentially by 2020 to be around 373 million units will be sold out globally $[7,8]$.

Regardless Of smartwatches' high scores on the 'hype-ometer', empirical examinations on how consumers' view and behavior of purchasing intention of these devices have not been satisfactorily conducted, and related research are still precursive. To fill this identified gap, present research has examined number of proximate psychological factors such as social influence, visibility, and cost that how these factors affect the determination of the user adoption and purchasing intention of smartwatches by assimilating them with technology acceptance model. This research thus aims to design a research model permitting a systematic estimation of smartwatch adoption and purchasing intention, with significant implications for manufacturers, marketing, and policy makers toward future wearable technology adoption.

\section{Literature review}

\subsection{Wearable devices and smartwatches}

A study conducted by [1] exposed that the terms 'wearable devices' or 'Wearable technologies', or just 'wearables' refers to 
contemporary micro-electronics or even computers that are smartly integrated into daily use accessories relevant to clothing and hence can be wore or attached to body. These characteristics deliver the consumers a seamless and integrated experience. It has been commonly observed that wearable devices provide significant convenience when compared to laptops and mobile phones. This quality can be rightly attribute to their light weight, easily accessible in nature, can be used while moving, nonkeyboard commands and control such as voice and gesture. Another worth mentioned significance of these devices is that they are simultaneously considered as technology and fashion by large number of users [9]. Further, in terms of performance, these devices can outperform than laptops and a smart phone, consequently the researcher thinks that they can easily replace the competitors in future. The author in [10] argues that awareness and knowledge these devices have been increased, which is positively affecting manufacturers intentions to release new versions of wearable technologies to the market. It has been argued that wearable devices possess significant potential for dramatically changing the landscape for societies and businesses as they can largely add to individuals' wellbeing and ultimately help them to make relatively batter and rational decision. Such as, smart wearable's in medical centers can help through providing most accurate health information that will ultimately increase patients' safety and success of medical operations.

The relevant published research does not provide any clarifying description of smartwatch technology. Such as, [8] discussed number of wearable's involving Samsung Galaxy Gear and Fitbit Flex, as smartwatches. While most of these are wristworn technologies, and technically other distinctions are required to mark them as smartwatches. Such as smart bracelets, smart wristband or fitness tracker are technically made for tracking the physical functions of the user and provide limited information in small displays. Hence these devices are primarily designed for compilation of limited data that a user can perform some analysis using laptop or smartphone. Further the capabilities of these are very limited in terms of presentation of information's such as pulse or time; also, the wristbands do not allow the installation of new applications. Contrary to that the smartwatches have relatively larger display and are mostly designed in larger size then traditional watches. In-addition, smartwatches are equipped with advance technology of touch screens, they allowed the users to install new apps. Another remarkable difference in wristband and smartwatches is that the latter provide extra functionality when user is connected to Internet. Smartwatches are capable for providing Facebook notifications, emails etc. while the primary function of wristbands is to gather data. In line with the conclusion of [11] our discussion reveals that smartwatches are relatively good choice as compare to wristbands hence, present work defines smartwatches as a device that is wore similar to regular watch and permits for apps installation and utilize the relevant features. In addition, an academic work was conducted by [12] on the wearable technologies and smartwatches' adoption, highlighting the impact of usefulness and visibility, their study revealed that perceived usefulness and visibility are important determinants that influence adoption among consumers. However, their study didn't test or examine consumers' intention to purchase the smartwatches, and the impact of adoption intention on purchasing decision. Which this study will reveal and tend to contribute and fill this literature gap.

\subsection{Theoretical framework and research model development}

The contemporary era has been experiencing the invention and innovation of different types of technologies; the technologies are commercialized on large scales that are leading to the development of different theoretical and conceptual models to explain the technology acceptance. One of the frequently discussed and used theoretical models is Technology Acceptance Model (TAM) that provides insights into final user's acceptance of ICT. This model postulate that the primary and prominent psychological factors of intention to use (ITU) are perceived ease of use (PEOU) and perceived usefulness (PU) [13,14]. It has been argued that when final end users perceived that a service is relatively easy to use and operate, they will use the technology. Number of earlier works done in the current area of interests suggests that TAM framework has the advantage of explanatory power and follow a parsimonious approach, this has been proved through many research works on the user adoption of several mobile-services and technologies, including m-government or smart government apps, tablet computers, e-book readers, mobile cloud computing, long-term evolution services (LTE), and digital currencies $[8,15-21]$. Consequently, TAM has been adopted as the primary theoretical framework to investigate the user acceptance of smartwatches. The following hypotheses have been developed in the current study.

H1: Perceived usefulness (PU) will have positive effect on users' intentions to use smartwatches (ITU).

H2: Perceived ease of use (PEOU) will have positive effect on users' intentions to use smartwatches (ITU).

\subsection{Visibility}

In contemporaneous societies, clothing, trinkets, and makeup are considered as important and prominent determinants of persons' imprint development e.g., [22-24]. A study carried out by [25] outlined first person verdicts as instant rejoinders during first meetings and considered that the noticeable factors of ones' personality plays an important role in impression structure. Earlier studies on possessions and branding exposed the ideology that visible components of personality can be used for impression and gathering data about others e. g. [26,27]. Hence, a user using a brand, or possession or product to reveal a facet of her/himself to others, wants to make sure that other people acknowledge such possession. As concluded by [28] "visible products and services are the bases for inferences about the status, personality, and disposition of the owner or consumer of these goods." As a contemporary trend, people tend to purchase products with high social status [29], the study presumes that people with more information's and awareness regarding visibility have a positive mindset towards a technology, others' influence may enhance consumers' intention [12,30-32]. Following this prior explanation, it is hypothesized:

H3: Visibility (VB) will have a positive effect on users' intention to use smartwatches (ITU).

\subsection{Social influence}

It has been observed that social influence is a significantly important factor, considering the technology has fashion factor 
involved as well. This is the case with most of the wearable devices such as smartwatches. Consequently, as soon as users tend to buy something, they do consider their social circles and social networks. Number of earlier relevant studies included social influence as a critical factor of the consumer buying behavior [15,33]. Two independent studies conducted by [34,35] investigate the adoption of wearable devices by passengers and concluded that social influence significantly affect behavioral intention. They further discussed that the social influence can greatly affect these systems because people normally tend to notice and that these devices will greatly increase their survival chances. Other studies have also confirmed that same for other wearable technologies such as smart clothing [36], smart glasses [37,38], and fitness/health wearable technologies [39-42]. Hence, it is hypothesized:

H4: Social influence (SI) will have a positive effect on users' intention to use smartwatches (ITU).

\subsection{Cost}

Cost is also considered as a vital factor in previous studies. whether consumers think that the smartwatches are costly or reasonable? whether they are willing to pay or not? Manufactures and all those concerns give high weightage to these questions because they know that consumer buying behavior is greatly influenced by consumers' opinions of cost. In fact, [43] attempted to analyze the nexus between cost and acceptance of m-banking. They reach to the conclusion that higher the cost of a service, less the consumers will be willing to purchase it. Similar results were exposed by number of other studies such as in case of mcommerce $[44,45]$. Considering the above, cost of smartwatches has been included as an explanatory variable with the following hypothesis to test its validity:

H5: Cost (CT) will have negative effect on intentions to purchase smartwatches (PI).

\subsection{Purchase intention}

Attitudes towards technology (i.e. intention to use) are the only determinants of purchasing intention, claims [46]. CostaFont, [47] also articulate that certain attitudes encourage consumers' choice of a product. These claims are widely supported in literature on technology adoption. These claims are well validated by empirical results showing strong associations $[48,49]$. Also, based on Davis' technology acceptance model, the author will test the correlation between intention to use and purchase intention. H6: Intention to use (ITU) smartwatches will have a positive effect on consumers' purchasing intention (PI).

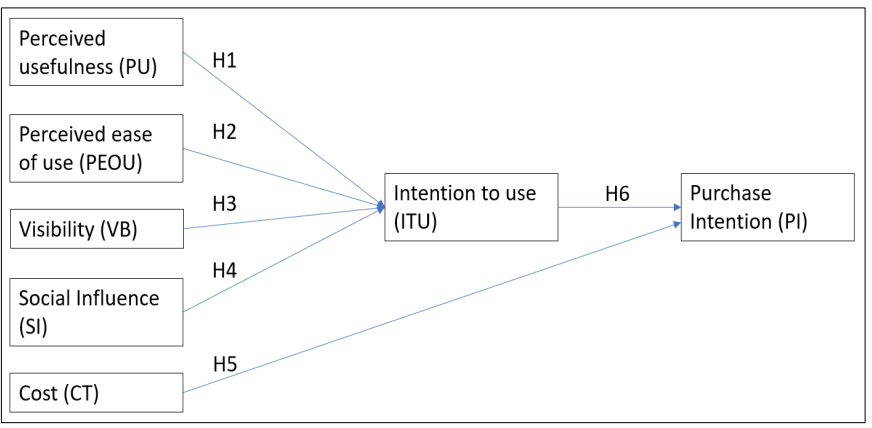

Figure 1: Conceptual framework of the research

\section{Methodology}

To the best of author's awareness, this is a pioneering empirical study that has exclusively attempted to scholarly examined the determinants of smartwatches buying intention of the people in the context of UAE. Present study has adopted an empirical approach for testing the model used, a well-designed and pretested questionnaire has been used for collecting the desired data on the proposed variables.

\subsection{Instruments}

The questionnaire served in this study has been divided into three sections. Introduction to the study and objectives of the study are given in first section, this was inevitable as respondents were UAE citizens (expats and locals). The next section was composed of questions related to demographic information's such as age, education, gender, and possession. And the final section was composed to 23 questions that measured seven variables drawn from relevant studies. All this has added significantly to the validity of instrument and ultimately to the reliability. Present study has extended the TAM model through inclusion of PU and PEOU to the predicted variables from the available literature, which are cost, social influence, and visibility. Table 2 has been allocated to the items' distribution that contains means and standard deviations of the items. It has been observed that this technique has added significantly in enhancement the consistency and strength of study's model.

\subsection{Sampling process}

The survey used in this research has been developed as follow: initially the researcher conducted a reliability test through collecting data from limited number participant from the target population (50 to 60) minimum. For this purpose, Cronbach's alpha was obtained from SmartPLS3. For justification of and deciding upon sample size, the researcher pre-planned that the survey will be distributed through electronic targeting to connect minimum 50 responses if possible. Consequently, to compel with the SmartPLS3 criteria of 10-times larger formative indicator for measuring single construct, or even highest order structural path that was indicated by the construct in the structural model.

Followed by that, the scholar has shared the survey link to the participants using the email list given by the University of Dubai. This simple random sampling method resulted in 106 responses after discarding incomplete responses, that is sufficient for the generalization and of results and sustainability of terms. Table 1 has been allocated to presents the sample demographics.

\subsection{Analysis of the results}

Partial least squares analysis which is based on structural equation modelling (SEM) [50]. SEM methodology has the advantage of assessing the measurement and structuring model simultaneously, hence factor analysis and hypothesis testing are done concurrently [51]. Further, PLS was used instead of covariance-based SEM as it is more appropriate for exploratory study [51]. For ensuring significant perceivability of the items used in the model, the Likert scale with responses recorded from 1 to 5 has been used. Table 2 presents information regarding loadings, cross-loadings, standard deviation, and means of all the variables used in the model. 
Table 1: Sample Table

\begin{tabular}{|l|l|l|}
\hline Gender & Frequency & Percentage \\
\hline Male & 65 & $61 \%$ \\
\hline Female & 41 & $39 \%$ \\
\hline Education & & \\
\hline High school & 3 & $3 \%$ \\
\hline Diploma & 8 & $8 \%$ \\
\hline Bachelor & 52 & $49 \%$ \\
\hline Postgraduate & 43 & $41 \%$ \\
\hline Age & & \\
\hline$>18$ & 1 & $1 \%$ \\
\hline $18-24$ & 26 & $25 \%$ \\
\hline $25-34$ & 32 & $30 \%$ \\
\hline $35-44$ & 38 & $36 \%$ \\
\hline $45-54$ & 7 & $7 \%$ \\
\hline $55-64$ & 2 & $2 \%$ \\
\hline
\end{tabular}

The scholar has properly measured the discriminant and convergent validities for examining the research model used in the research. For verification and validity of convergent strength, the average variance extracted was performed, for internal consistency Cronbach's Alpha and item loadings were obtained. All of these statistics were higher than 0.70 for composite reliabilities, the Cronbach's Alpha was above 50 percent, the statistic for item loadings was 0.70 [52] all these are given in Table 2 and 3. Further, Table 2 shows that average loading of variables is higher than 70 percent; this is desirable in social sciences. Further, the acceptable level dependency of all variables has been shown by Cronbach's alpha (suggested value 0.8, acceptable value 0.6 ) the details of these values are given in Table 2 .

Technically, prior to responding the research question, the scholar should examine and test for the possible correlation. Agreeing to [53] for the discriminant validity, as compare to a construct correlation with other variables, the AVE must be larger for every construct. Table 3 present the results for inter-construct correlation matrix, with bold values representing the respective square root AVE.

A Simultaneous equation model test has been applied using SmartPLS3 to add further to the results shown and to properly achieve the research aim. Technically, the non-parametric bootstrapping procedure is used by PLS-SEM for statistically testing the model under consideration. In simple words, numbers of sub-samples out of the study sample are produced and are tested for the verification and validity of model best fit. The University of Dubai has its own licensed SmartPLS3 tool that is used by the scholars. The output is presented in Table 3 .

A great significance of SmartPLS3 tool is that it simultaneously computes the t-statistic and exact probability value p-value for each hypothesis tested. The results are provided in Table 4.

For obtaining the t-values, the bootstrapping procedure was utilized. The coefficient of determination $R^{2}$ value of 0.69 suggests that the model is good fit. Further, Figure 2 provides partial coefficient values along with their respective ' $t$ ' and ' $p$ ' values.

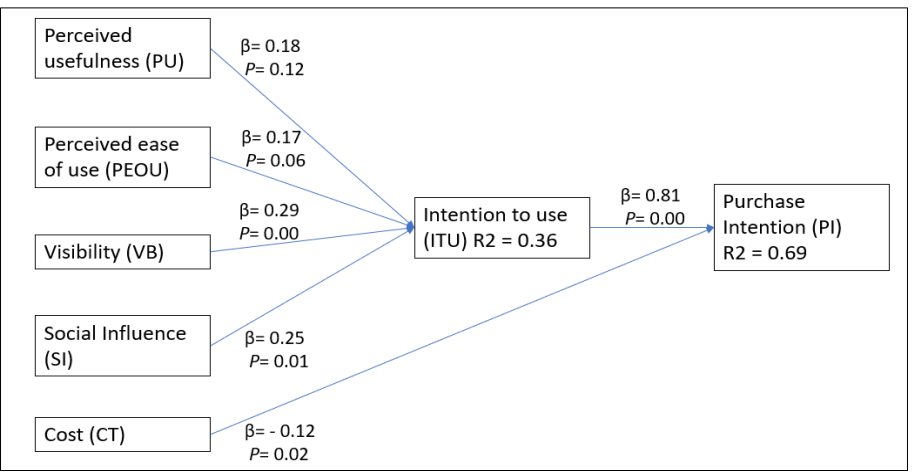

Figure 2. Hypotheses' $b$ - and $p$-values

\section{Discussion}

As users' interest in smartwatches has lately become obvious, increasing assurance has been placed on the determinants that facilitate consumers' experience and boost greater adoption of smartwatches. Consequently, this research investigates smartwatches' key psychological and technological determinants trying to understand consumers' behavior, and explores their effect on smartwatches purchasing intention, by designing and confirming an integrated user adoption model. The model explains that people at the UAE will tend to purchase smartwatches for less cost (CT) of course, and other factors mediated by intention to use (ITU), which are visibility (VB), social influence (SI) and of course such technology should be easy to use (PEOU). The first variable (PI) is a well-explored construct that is used as a surrogate for smartwatch purchasing. In this study, PI was predicted by two major variables (ITU) and (CT), with a varying degree of significance. It was found that three out of four variables mediated by (ITU) which have significant indirect effect on (PI), these are (PEOU), (SI), and (VB). Only one of the variables was found not to be significant, which is (PU).

The analysis reveals that the prominent construct of PI is the intention to use (ITU), with partial coefficient value of 0.81 . This suggests that the more the people of UAE have the intention to use technology, the more they will purchase smartwatches. Further, the analysis shows that, cost (CT) is another dominant explanatory factor of PI, with partial coefficient value of -0.12 . This suggests that higher the cost, lower will be purchase intent of the people and vice versa, as the peoples in UAE consider price or cost to be a major factor that shape their future buying decision. In addition, and as per the results analysis above, there were critical predictors have significant indirect influence on people purchasing intention, mediated by ITU. These are VB, SI, PEOU in order. Visibility found to be important predictor with beta value 0.29 . This suggests that in the context of UAE, people care about visibility (VB) of wearable technologies, i.e., they care about how people will notice in case they wear smartwatch and they do believe that smartwatches are more visible and prominent. Consequently, they have greater intention to use smartwatches. Similar finding was discussed by [12] on the significance of VB on ITU. These results support the findings of [12] that smartwatches, merge technology and fashion aspects. 
Table 2: Means, standard deviations, and item measurement loadings and cross loadings of the variables. And internal validity

\begin{tabular}{|c|c|c|c|c|c|c|c|}
\hline & \multicolumn{7}{|c|}{ Measurement item outer loadings } \\
\hline Item & ITU & CT & PEOU & PI & $\mathrm{PU}$ & SI & VB \\
\hline ITU1 & 0.917 & -0.137 & 0.356 & 0.688 & 0.44 & 0.328 & 0.366 \\
\hline ITU2 & 0.955 & -0.111 & 0.372 & 0.805 & 0.437 & 0.393 & 0.329 \\
\hline ITU3 & 0.895 & -0.079 & 0.311 & 0.786 & 0.381 & 0.377 & 0.422 \\
\hline PC1 & -0.103 & 0.862 & -0.022 & -0.167 & 0.058 & 0.072 & 0.076 \\
\hline PC2 & -0.122 & 0.925 & -0.099 & -0.226 & 0.019 & -0.048 & -0.019 \\
\hline PC3 & -0.077 & 0.834 & 0.002 & -0.159 & -0.037 & 0.017 & 0.025 \\
\hline PEOU1 & 0.379 & -0.099 & 0.88 & 0.426 & 0.405 & 0.243 & 0.249 \\
\hline PEOU2 & 0.339 & 0.026 & 0.911 & 0.346 & 0.323 & 0.194 & 0.182 \\
\hline PEOU3 & 0.266 & -0.068 & 0.887 & 0.322 & 0.438 & 0.178 & 0.145 \\
\hline PI1 & 0.861 & -0.117 & 0.344 & 0.901 & 0.471 & 0.393 & 0.365 \\
\hline PI2 & 0.768 & -0.159 & 0.436 & 0.916 & 0.461 & 0.464 & 0.252 \\
\hline PI3 & 0.675 & -0.302 & 0.424 & 0.914 & 0.409 & 0.371 & 0.262 \\
\hline PI4 & 0.726 & -0.225 & 0.362 & 0.924 & 0.382 & 0.444 & 0.336 \\
\hline PI5 & 0.808 & -0.194 & 0.362 & 0.942 & 0.46 & 0.43 & 0.291 \\
\hline PI6 & 0.702 & -0.212 & 0.373 & 0.933 & 0.446 & 0.505 & 0.226 \\
\hline PU1 & 0.366 & 0.047 & 0.397 & 0.375 & 0.714 & 0.216 & 0.31 \\
\hline PU2 & 0.358 & 0.041 & 0.239 & 0.311 & 0.829 & 0.352 & 0.209 \\
\hline PU3 & 0.42 & 0.049 & 0.382 & 0.434 & 0.87 & 0.439 & 0.235 \\
\hline PU4 & 0.336 & -0.013 & 0.365 & 0.372 & 0.853 & 0.455 & 0.228 \\
\hline PU5 & 0.391 & -0.057 & 0.401 & 0.473 & 0.876 & 0.444 & 0.184 \\
\hline SI1 & 0.343 & 0.02 & 0.225 & 0.482 & 0.462 & 0.897 & 0.025 \\
\hline SI2 & 0.351 & 0.014 & 0.188 & 0.357 & 0.358 & 0.939 & 0.079 \\
\hline SI3 & 0.388 & -0.009 & 0.222 & 0.443 & 0.435 & 0.889 & 0.121 \\
\hline VB1 & 0.389 & 0.07 & 0.198 & 0.328 & 0.257 & 0.126 & 0.885 \\
\hline VB2 & 0.297 & 0.059 & 0.193 & 0.206 & 0.197 & -0.045 & 0.855 \\
\hline VB3 & 0.359 & -0.06 & 0.191 & 0.278 & 0.272 & 0.117 & 0.878 \\
\hline $\begin{array}{l}\text { Cronbach's } \\
\text { alpha }\end{array}$ & 0.91 & 0.85 & 0.87 & 0.97 & 0.89 & 0.89 & 0.84 \\
\hline $\begin{array}{l}\text { Composite } \\
\text { reliability }\end{array}$ & 0.95 & 0.91 & 0.92 & 0.97 & 0.92 & 0.93 & 0.91 \\
\hline AVE & 0.85 & 0.76 & 0.80 & 0.85 & 0.69 & 0.83 & 0.76 \\
\hline
\end{tabular}

Table 3: Discriminant validity

\begin{tabular}{|l|r|r|r|r|r|r|r|}
\hline & \multicolumn{1}{|l|}{ ITU } & \multicolumn{1}{l|}{ CT } & PEOU & PI & PU & \multicolumn{1}{l|}{ SI } & Visibility \\
\hline ITU & $\mathbf{0 . 9 2 3}$ & & & & & & \\
\hline CT & -0.117 & $\mathbf{0 . 8 7 4}$ & & & & & \\
\hline PEOU & 0.375 & -0.053 & $\mathbf{0 . 8 9 3}$ & & & & \\
\hline PI & 0.826 & -0.215 & 0.415 & $\mathbf{0 . 9 2 2}$ & & & \\
\hline PU & 0.454 & 0.017 & 0.432 & 0.477 & $\mathbf{0 . 8 3}$ & & \\
\hline SI & 0.398 & 0.008 & 0.234 & 0.471 & 0.461 & $\mathbf{0 . 9 0 9}$ & \\
\hline Visibility & 0.403 & 0.026 & 0.222 & 0.316 & 0.28 & 0.085 & $\mathbf{0 . 8 7 3}$ \\
\hline
\end{tabular}


Table 4: $T$-values and $p$-values with hypothesis status

\begin{tabular}{|c|c|c|c|c|}
\hline Hypotheses & Path coefficient & $T$-value & $P$-value & Hypothesis status \\
\hline $\mathrm{PU} \longrightarrow \mathrm{ITU}$ & 0.18 & 1.55 & 0.12 & Not supported \\
\hline $\mathrm{PEOU} \longrightarrow \mathrm{ITU}$ & 0.17 & 1.84 & 0.06 & Supported $*$ \\
\hline $\mathrm{SI} \longrightarrow \mathrm{ITU}$ & 0.25 & 2.46 & 0.01 & Supported $* *$ \\
\hline $\mathrm{VB} \longrightarrow \mathrm{ITU}$ & 0.29 & 3.42 & 0.00 & Supported $* * *$ \\
\hline $\mathrm{CT} \longrightarrow \mathrm{PI}$ & -0.12 & 2.25 & 0.02 & Supported ** \\
\hline ITU $\longrightarrow$ PI & 0.81 & 23.05 & 0.00 & Supported *** \\
\hline
\end{tabular}

The analysis exposed that social influence (SI) has significant impact on PI with the partial coefficient value of 0.25 . This outcome leads us to conclude that in the context of UAE economy, peoples attach more importance to social influence and will have more intention to purchase smartwatches if they consider the influence of closed or important ones, such as family, relatives, colleagues, and important people at the society such as social influencers. A person in UAE will purchase smartwatch, if s/he notice that people important in her/his life thinks that s/he should have a smartwatch. Technically, bandwagon effect can be observed in case of smartwatches purchases in UAE.

Similarly, the analysis suggests that perceived ease of use (PEOU) significantly influence ITU with a partial coefficient value of 0.17 , suggesting that ease of use is as major determinant of buying behavior in UAE. People give importance to acquiring knowledge about how to use and operate smartwatches. It has been observed that perceived usefulness (PU) has no significant relationship with (PI) in the context of UAE economy. This outcome can be explained by number of factors involved, first, most of the peoples think that smartwatches are not important as have already been receiving notifications through their mobile phones, further facilities such as heartbeat rate is available in most of the smart phones as well as in most of other wearable technologies. Further, battery drain is a significant problem as people do not like to charge their smartwatches on daily basis or even every next day. All these explains why PU is not a significant factor in the context of UAE economy, and Similar finding was reported [8].

The analysis suggests that $69 \%$ of the variation in PI is explained by the included variables in the model, in social sciences that is considered as a substantial level of prediction. Out of the six variables included in the model as predictors of intention to use (ITU), four variables namely CT, PEOU, SI, were found to have statistically significant relationship with ITU and one variable PU was found not significant. Further, table 5 suggests that all but (H1) of the proposed hypotheses were supported.

Most the variables included in the present study are significantly important for analyzing smartwatch adoption and purchasing behavior in the context of UAE. The findings of the current study are in line with the findings of the earlier studies in the field.

The study suggests that visibility and social influence play critical roles in shaping purchasing intention of the peoples in www.astesi.com
UAE; people are close together and influence each other via social perceptions. Further, in the context of UAE, people also care about others' impression on their wearable devices. Moreover, prior research works have also reported that cost of smartwatches is also important and is negatively influencing purchasing decision. Hence, manufacturers should give significant importance to prices of their products and should try to produce different types of products with different prices. Finally, it has been found that ease of use is another important determinant and consumer mostly prefers simple and easy to use smartwatches in terms of features and applications. However, perceived usefulness does not influence consumers' intention to use smartwatches, subsequently buying behavior them. As many people believed that smartwatches are not mature enough to replace some or main functions of smart phones yet, and it has some drawbacks discussed earlier.

\section{Conclusion}

\subsection{Theoretical Contribution}

This research contributes two-folds to the existing stock of knowledge on the present area of interest. First, published scholarly research on smartwatches is relatively limited, and this study is an addition to limited research. Specifically, it added and validated the importance of technology acceptance utilizing (TAM) to predict the purchasing intention. In addition, TAM was combined with more variables such as cost, social influence to explain consumers' purchasing intention. Second, this work provides technical insights for understanding smartwatches, which are observed as from a technology and psychology viewpoint. Analysis suggests that most people consider smartwatches to be a combination of technology and fashion. Hence, visibility is an important determinant of adoption intention, and subsequently influence consumers' purchasing decision. However, TAM has not yet tackled the visibility part, while related aspects, such as image have been shown to be relevant in some contexts. The outcomes of the this study are in line with the previous work, which suggest that consumers perceive smartwatches on two dimensions: technology and fashion [12,33]. Generally, when exploring the adoption of purchasing intention of wearable technologies, using TAM, other variables i.e. (social influence, visibility, and cost) should be considered. Just as, any smart T-shirt or smart shoes may be considered relatively more fashion related than technology. Consequently, the relevant 
theories about fashion adoption may work more appropriately in this case.

\subsection{Practical contribution}

It has been argued that smartwatches are a combination of technology and fashion, and they are supposed to accordingly be well-designed, affordable, and meet social needs of their targeted consumers. Despite limited customization of the design, majority of smartwatches offer technical customizations through installation of applications. To take full advantage of their market competitiveness, manufacturers are offering their products in variety of colors or wristband, whereas other are advertising various virtual background on the screen. In addition, manufacturers, should pay attention to the cost factor, which is critical, or they might introduce different models with differ prices. While the focus of this study is on smartwatches, it provides a guidance and managerial implications for decision makers for manufacturers and their marketing, not only on smartwatches, but also, on other wearable devices, for example smart glasses, smart shoes, or smart clothing.

\section{Limitation and Future Research}

Similar to other scholarly works, present study has number of delimitations that needs to be addressed in future research. First, as current study has taken sample from single country, the allows the researcher to control number of exogenous factors, which results an increase in internal validity, and thus limits the generalizability of the study. Although, previous studies carried out in this regard exposed that TAM [54] and other models associated with visibility $[55,56]$ are considerably steady in varying samples and contexts, making this restriction less threatening for the sustainability of present study. furthermore, the inclusion of non-branded smartwatches allows consumers to express openly the influence on their intention without being potentially biased by a particular smartwatches brand.

Nevertheless, this advantage relates to the limitation with brand related issues, for instance brand loyalty, was not considered. For example, it was argued that a user with high brand attachment [57] or brand love [58] to Apple, would purchase any product of Apple. Upcoming studies should concentrate on tackling such limitations. Moreover, further evaluation of the significance of visibility is necessary. For example, particular design features i.e., color, shape, size) might be examined to verify the ideal strategy and improve the understanding of the desired visibility.

Correspondingly, the functions of smartwatches and its benefits, could be further studied to expose perceived usefulness (PU). Lastly, forthcoming studies might apply resistance models i.e. [59] to recognize the resistance to smartwatches and/wearable technologies. These models might be crucial in situation where smartwatches substitute conventional watches.

\section{Conflict of Interest}

The authors declare no conflict of interest.

\section{References}

[1] R. Wright, L. Keith, "Wearable technology: If the tech fits, wear it," Journal of Electronic Resources in Medical Libraries, 11(4), 204-216.
[2] M. Swan, "Sensor mania! the internet of things, wearable computing, objective metrics, and the quantified self 2.0," Journal of Sensor and Actuator Networks, 1(3), 217-253.

[3] P. Castillejo, J.F. Martínez, L. López, G. Rubio, "An internet of things approach for managing smart services provided by wearable devices," International Journal of Distributed Sensor Networks, 9(2), 190813.

[4] S. Hiremath, G. Yang, K. Mankodiya, "Wearable Internet of Things: Concept, architectural components and promises for person-centered healthcare," in 2014 4th International Conference on Wireless Mobile Communication and Healthcare-Transforming Healthcare Through Innovations in Mobile and Wireless Technologies (MOBIHEALTH, IEEE: 304-307.

[5] A. Sun, T. Ji, J. Wang, H. Liu, "Wearable mobile internet devices involved in big data solution for education," International Journal of Embedded Systems, 8(4), 293-299.

[6] A. McIntyre, Wearable computing in the workplace to be dependent on apps and services, 19-24.

[7] T. Danova, "Why the smart watch market is poised to explode as it draws millions of consumers into wearable computing," Business Insider, 1-18.

[8] K.J. Kim, D.H. Shin, "An acceptance model for smart watches," Internet Research,.

[9] D.W. Hein, P.A. Rauschnabel, Augmented reality smart glasses and knowledge management: A conceptual framework for enterprise social networks, Springer Gabler, Wiesbaden: 83-109.

[10] S. Park, K. Chung, S. Jayaraman, Wearables: Fundamentals, advancements, and a roadmap for the future, Academic Press: 1-23.

[11] M.E. Cecchinato, A.L. Cox, J. Bird, "Smartwatches: the Good, the Bad and the Ugly?," in Proceedings of the 33rd Annual ACM Conference extended abstracts on human factors in computing systems, 2133-2138.

[12] S.H.W. Chuah, P.A. Rauschnabel, N. Krey, B. Nguyen, T. Ramayah, S. Lade, "Wearable technologies: The role of usefulness and visibility in smartwatch adoption," Computers in Human Behavior, 65, 276-284. https://doi.org/10.1016/j.chb.2016.07.047

[13] F.D. Davis, "Perceived usefulness, perceived ease of use, and user acceptance of information technology," MIS Quarterly, 319-340.

[14] F.D. Davis, "User acceptance of information technology: system characteristics, user perceptions and behavioral impacts," International Journal of Man-Machine Studies, 38(3), 475-487.

[15] J. Jung, S. Chan-Olmsted, B. Park, Y. Kim, "Factors affecting e-book reader awareness, interest, and intention to use," New Media \& Society, 14(2), 204 224.

[16] E. Park, K.J. Kim, "User acceptance of long-term evolution (LTE) services," Program,

[17] E. Park, A.P. Pobil, "Technology acceptance model for the use of tablet PCs," Wireless Personal Communications, 73(4), 1561-1572.

[18] J. Joo, Y. Sang, "Exploring Koreans' smartphone usage: An integrated model of the technology acceptance model and uses and gratifications theory," Computers in Human Behavior, 29(6), 2512-2518.

[19] K.J. Kim, S.S. Sundar, "Does screen size matter for smartphones? Utilitarian and hedonic effects of screen size on smartphone adoption," Cyberpsychology, Behavior, and Social Networking, 17(7), 466-473.

[20] N.A.S. Almuraqab, "M-Government adoption factors in the UAE: a partial least squares approach," International Journal of Business and Information, 11(4).

[21] N.A. Saif Almuraqab, "Predicting determinants of the intention to use digital currency in the UAE: An empirical study," The Electronic Journal of Information Systems in Developing Countries, 86(3), 12125. https://doi.org/10.1016/j.cb.2016.078956

[22] H.L. Douty, "Influence of clothing on perception of persons," Journal of Home Economics, 55(3), 197-202.

[23] N. Judd, R.H.C. Bull, D. Gahagan, "The effects of clothing style upon the reactions of a stranger," Social Behavior and Personality: An International Journal, 3(2), 225-227.

[24] R.H. Holman, Clothing as communication: an empirical investigation, ACR North American Advances.

[25] H.W. Bierhoff, R. Klein, Reasoning in Impression Formation, Springer, Berlin, Heidelberg: 77-105.

[26] R.W. Belk, Effects of consistency of visible consumption patterns on impression formation, ACR North American Advances.

[27] B.M. Fennis, A.T.H. Pruyn, "You are what you wear: Brand personality influences on consumer impression formation," Journal of Business Research, 60(6), 634-639. https://doi.org/10.1016/j.jbusres.2006.06.013

[28] R.W. Belk, Assessing the effects of visible consumption on impression formation, ACR North American Advances.

[29] K. Wilcox, H.M. Kim, S. Sen, "Why do consumers buy counterfeit luxury 
brands?," Journal of Marketing Research, 46(2), 247-259.

[30] H. Nysveen, P.E. Pedersen, H. Thorbjørnsen, "Intentions to use mobile services: Antecedents and cross-service comparisons," Journal of the Academy of Marketing Science, 33(3), 330-346. https://doi.org/10.1177\%2F0092070305276149

[31] A. Eckhardt, S. Laumer, T. Weitzel, "Who influences whom? Analyzing workplace referents' social influence on IT adoption and non-adoption," Journal of Information Technology, 24(1), 11-24, 2015. https://doi.org/10.1057\%2Fjit.2008.31

[32] S. Sawang, Y. Sun, S.A. Salim, "It's not only what I think but what they think! The moderating effect of social norms," Computers \& Education, 76, $182-189$.

[33] H. Yang, J. Yu, H. Zo, M. Choi, "User acceptance of wearable devices: An extended perspective of perceived value," Telematics and Informatics, 33(2), 256-269, 2016. https://doi.org/10.1016/j.tele.2015.08.007

[34] L.H. Wu, L.C. Wu, S.C. Chang, "Exploring consumers' intention to accept smartwatch," Computers in Human Behavior, 64, 383-392.

[35] S.T. Kwee-Meier, J.E. Bützler, C. Schlick, "Development and validation of a technology acceptance model for safety-enhancing, wearable locating systems," Behaviour \& Information Technology, 35(5), 394- 409.

[36] G. Turhan, "An assessment towards the acceptance of wearable technology to consumers in Turkey: the application to smart bra and t-shirt products," Journal of the Textile Institute, 104(4), 375-395.

[37] P.A. Rauschnabel, A. Brem, B.S. Ivens, "Who will buy smart glasses? Empirical results of two pre-market-entry studies on the role of personality in individual awareness and intended adoption of Google Glass wearables," Computers in Human Behavior, 49, 635-647, 2010. https://doi.org/10.1016/j.chb.2015.03.003

[38] M. Kalantari, P. Rauschnabel, Exploring the early adopters of augmented reality smart glasses: The case of Microsoft HoloLens, Springer, Cham: 229245.

[39] L. Wu, J.Y. Li, C.Y. Fu, "The adoption of mobile healthcare by hospital's professionals: An integrative perspective," Decision Support Systems, 51(3), 587-596.

[40] K. Jang Yul, Determinants of Users Intention to Adopt Mobile Fitness Applications: an Extended Technology Acceptance Model Approach.

[41] X. Wang, L. White, X. Chen, Y. Gao, H. Li, Y. Luo, "An empirical study of wearable technology acceptance in healthcare," Industrial Management \& Data Systems,

[42] A.I. Canhoto, S. Arp, "Exploring the factors that support adoption and sustained use of health and fitness wearables," Journal of Marketing Management, 33(1-2), 32-60.

[43] P. Luarn, H.H. Lin, "Toward an understanding of the behavioral intention to use mobile banking," Computers in Human Behavior, 21(6), 873-891.

[44] S.Y. Hung, C.Y. Ku, C.M. Chang, "Critical factors of WAP services adoption: an empirical study," Electronic Commerce Research and Applications, 2(1), 42-60.

[45] J.-H. Wu, S.-C. Wang, "What drives mobile commerce?: An empirical evaluation of the revised technology acceptance model," Information \& Management, 42(5), 719-729. https://doi.org/10.1016/j.cb.2015.03.003

[46] L. Bredahl, "Determinants of consumer attitudes and purchase intentions with regard to genetically modified food-results of a cross-national survey," Journal of Consumer Policy, 24(1), 23-61.

[47] M. Costa-Font, J.M. Gil, W.B. Traill, "Consumer acceptance, valuation of and attitudes towards genetically modified food: Review and implications for food policy," Food Policy, 33(2), 99-111.

[48] C. Yue, S. Zhao, C. Cummings, J. Kuzma, "Investigating factors influencing consumer willingness to buy GM food and nano-food," Journal of Nanoparticle Research, 17(7), 283.

[49] F.A. Yamoah, R. Duffy, D. Petrovici, A. Fearne, "Towards a framework for understanding fairtrade purchase intention in the mainstream environment of supermarkets," Journal of Business Ethics, 136(1), 181-197.

[50] C.M. Ringle, S. Wende, S. Will, SmartPLS 2.0 (M3) Beta.

[51] D. Gefen, D. Straub, M.C. Boudreau, "Structural equation modeling and regression: Guidelines for research practice," Communications of the Association for Information Systems, 4(1), 7.

[52] J.F. Hair, W.C. Black, B.J. Babin, R.E. Anderson, R. Tatham, Multivariate data analysis.

[53] C. Fornell, D.F. Larcker, "Evaluating structural equation models with unobservable variables and measurement error," Journal of Marketing Research, 18(1), 39-50.

[54] W.R. King, J. He, "A meta-analysis of the technology acceptance model," Information \& Management, 43(6), 740-755.

[55] J.L. Nueno, J.A. Quelch, "The mass marketing of luxury," Business Horizons, 41(6), 61-61.
[56] F. Vigneron, L.W. Johnson, "Measuring perceptions of brand luxury," Journal of Brand Management, 11(6), 484-506.

[57] S. Belaid, A.T. Behi, "The role of attachment in building consumer-brand relationships: an empirical investigation in the utilitarian consumption context," Journal of Product \& Brand Management,.

[58] R. Batra, A. Ahuvia, R.P. Bagozzi, "Brand love," Journal of Marketing, 76(2), 1-16.

[59] P. Spreer, P.A. Rauschnabel, "Selling with technology: understanding the resistance to mobile sales assistant use in retailing," Journal of Personal Selling \& Sales Management, 36(3), 240-263, 2015. https://doi.org/10.1016/j.chb.2015.03.01203 